\title{
An offline-online Web-GIS Android application for fast data acquisition of landslide hazard and risk
}

\author{
Roya Olyazadeh $^{1}$, Karen Sudmeier-Rieux $^{1}$, Michel Jaboyedoff ${ }^{1}$, Marc-Henri Derron $^{1}$, and Sanjaya Devkota ${ }^{2}$ \\ ${ }^{1}$ University of Lausanne, ISTE - Institut des Sciences de la Terre, Faculté des géosciences et de l'environnement, \\ Lausanne, Switzerland \\ ${ }^{2}$ Department of Civil Engineering, Institute of Engineering, Tribhuvan University, Kathmandu, Nepal
}

Correspondence to: Roya Olyazadeh (roya.olyazadeh@unil.ch)

Received: 12 August 2016 - Discussion started: 29 August 2016

Revised: 14 March 2017 - Accepted: 21 March 2017 - Published: 13 April 2017

\begin{abstract}
Regional landslide assessments and mapping have been effectively pursued by research institutions, national and local governments, non-governmental organizations (NGOs), and different stakeholders for some time, and a wide range of methodologies and technologies have consequently been proposed. Land-use mapping and hazard event inventories are mostly created by remote-sensing data, subject to difficulties, such as accessibility and terrain, which need to be overcome. Likewise, landslide data acquisition for the field navigation can magnify the accuracy of databases and analysis. Open-source Web and mobile GIS tools can be used for improved ground-truthing of critical areas to improve the analysis of hazard patterns and triggering factors. This paper reviews the implementation and selected results of a secure mobile-map application called ROOMA (Rapid Offline-Online Mapping Application) for the rapid data collection of landslide hazard and risk. This prototype assists the quick creation of landslide inventory maps (LIMs) by collecting information on the type, feature, volume, date, and patterns of landslides using open-source Web-GIS technologies such as Leaflet maps, Cordova, GeoServer, PostgreSQL as the real DBMS (database management system), and PostGIS as its plug-in for spatial database management. This application comprises Leaflet maps coupled with satellite images as a base layer, drawing tools, geolocation (using GPS and the Internet), photo mapping, and event clustering. All the features and information are recorded into a GeoJSON text file in an offline version (Android) and subsequently uploaded to the online mode (using all browsers) with the availability of Internet. Finally, the events can be accessed and edited after
\end{abstract}

approval by an administrator and then be visualized by the general public.

\section{Introduction}

Landslides refer to all types of mass movements on slopes (Varnes, 1984) and can be triggered by various external events such as intense rainfall, earthquakes, water-level changes, storm waves, or human activities. The location, the time of event, and the types of movements can be recorded in a landslide inventory map (LIM). LIMs are important factors for hazard and risk assessments, particularly if there are a significant number of landslides with different types, dates, volumes, and trigging factors (Coe et al., 2004). They can be created using various methods; however the selection of techniques depends on the size of the area, the resolution, the scale of the map, land use, soil, and geomorphology (Coe et al., 2004; Guzzetti et al., 2006; Hungr et al., 2014). Documenting landslides is essential to defining landslide susceptibility, hazard, and risk, as well as for survey types, patterns, distributions, and statistics of slope failures. However, developing complete landslide inventories is difficult, due to accessibility, the dynamic nature of landslides, and also the time required (van Westen et al., 2006). Conventional techniques lead to the development of landslide inventories mainly based on the visual interpretation of satellite images, assisted by field surveys. Typical issues for creating these maps are listed below (van Westen et al., 2006; Safaei et al., 2010; Guzzetti et al., 2012). 
All methods for developing landslide inventories are resource-intensive and time-consuming (Guzzetti et al., 2012).

1. Landslides are often small with a high frequency of occurrence and located in remote areas which are difficult to access;

2. landslides often have different characteristics which require them to be mapped and documented individually;

3. the lack of landslide documentation and databases is the main issue in the evaluation of landslide hazard risk;

4. limited damage data are available for landslides, which is why developing landslide vulnerability assessments is challenging;

5. sources of landslide inventories - such as aerial photography, satellite imagery, InSAR (interferometric synthetic aperture radar), and lidar (light detection and ranging) - are expensive.

Several authors have described the role of GIS for landslide susceptibility and hazards with respect to the type of data available, landslide type, and potential extension (van Westen, 1993; Guzzetti, 2000; Van Den Eeckhaut et al., 2009; Carrara et al., 1991; Dhakal et al., 2000). While the above authors have noted the importance of enhanced mapping, mobile GIS offers technology with more effective ground-truthing and a rapid tool which can systematically fill a database, especially for inexperienced mappers. Currently, there is great potential to apply mobile GIS, including GPS and mapping tools, to significantly increase efficiencies in data collection such as location accuracy and detailed information of features.

In this paper, Rapid Offline-Online Mapping Application (ROOMA) based on geospatial open-source technologies is described to collect data on landslide events, hazard impacts, and damaged infrastructure, which can be made freely accessible to authorities, stakeholders, and the general public. An offline technology helps to map the events, especially in rural areas where Internet is not available. Furthermore, the preliminary result of this application is also compared to the results of satellite image interpolation. This prototype has following objectives:

1. an Android mobile application with the possibility of both offline and online access;

2. fast and easy data and information acquisition;

3. advanced visualization using satellite images and a drawing tool;

4. a central database with availability by different services (mobile phones, PCs (personal computers), and standard Web browsers);

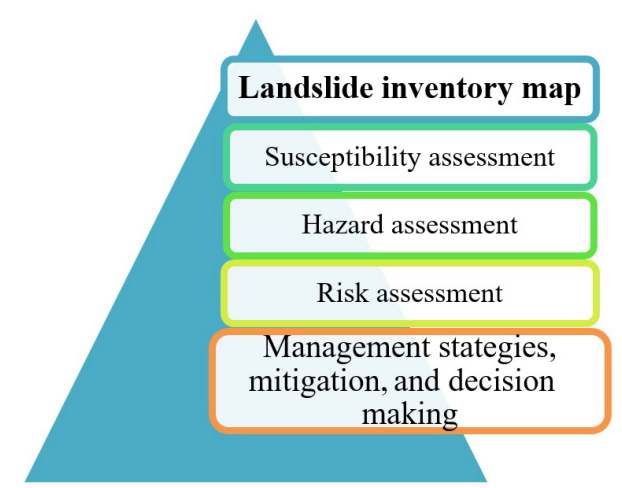

Figure 1. Landslide inventory maps are the origin for landslide hazard and risk (Dai et al., 2002; Fell et al., 2005).

5. data management improvement in hazard event mapping and storage using new technologies such as PostGIS and GeoServer.

The paper is structured as follows. In Sect. 2, we first present the background, the importance of landslide inventories maps in hazard and risk assessment, and principles of the different approaches for landslide inventory. We also review some GIS tools that simplify field navigation. Section 3 discusses the description of mapping method, with a field survey for preparation of LIMs in relation to elements at risks. Section 4 illustrates the architecture and platform using open-source geospatial technologies to map landslides by using an Android application. Sections 5 and 6 focus on the case study and results, respectively. Finally, Sect. 7 concludes by discussing the advantages of mobile GIS, with the future outlook of producing data on landslides.

\section{Background}

Landslide risk management estimates risk options with different levels of acceptance criteria. It includes estimations for various levels of risk, decisions on the acceptable level, recommendations, and implementation of suitable control measures to reduce risk. It requires that a number of key elements be addressed (Fig. 1): landslide inventory, susceptibility assessment, hazard assessment, risk assessment, management strategies, and decision making (Dai et al., 2002; Fell et al., 2005). Landslides present visible signs for reorganization, classification, and mapping in the field, completed by the interpretation of satellite imagery, aerial photography, or the topographic surface (Guzzetti et al., 2012). There are many methodologies for landslide hazard assessment using geospatial technologies (van Westen, 1993; Soeters and van Westen, 1996; Guzzetti, 2000; Dai et al., 2002; van Westen et al., 2006). The classification methods can be categorized as (1) landslide inventory methods (Soeters and van Westen, 1996; Galli et al., 2008; Sumaryono et al., 2014), (2) heuristic methods (Ruff and Czurda, 2008; van Westen et 

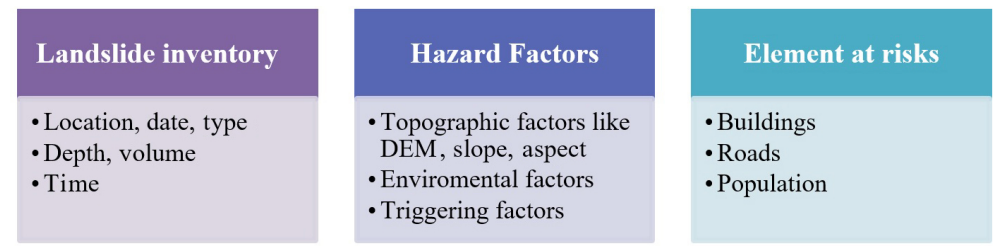

Figure 2. Database for landslide risk assessment and management (van Westen, 2004).

al., 2006; Safaei et al., 2010), (3) statistical methods (Huabin et al., 2005), and (4) deterministic methods (Hammond et al., 1992; Zhou et al., 2003). Landslide inventories are the simplest and the most straightforward initial form of mapping because they display the locations of recorded landslides, and they are a significant factor of most susceptibility mapping techniques and hazard assessments for qualitative and statistical analysis (Wieczorek, 1983; Dai et al., 2002; van Westen et al., 2006). They have a different purpose, which in addition to location also includes information and data on the type of landslides and triggering factors (e.g. earthquake or intense rainfall), and information on landslide susceptibility (Galli et al., 2008). They therefore have different techniques for preparation, including landslide distribution analysis, landslide activity analysis, and landslide density analysis (Soeters and van Westen, 1996).

\subsection{Landslide data collection}

Data collection includes desk and field studies and involves different activities ranging from low cost to expensive (Soeters and van Westen, 1996). The different techniques for data collection are divided into (1) image interpretation; (2) semi-automated classification; (3) automated classification; and (4) field navigation including total stations, GPS, and recently mobile GIS. Fieldwork is mostly carried out to classify groups of landslides triggered by an event, acquire data about characteristics of landslides, check inventory maps prepared by other methods, and improve visual interpretation of satellite images (van Westen et al., 2006, 2008; Safaei et al., 2010). Landslide inventories can be characterized by scale and the type of mapping (Guzzetti et al., 2006), and they are developed by gathering historic information on different landslide events or remote-sensing (RS) data (i.e. satellite imagery and aerial photographs) together with field verification using GPS (Soeters and van Westen, 1996). There are some examples of different methods using RS, lidar, and comparisons of inventory maps (Galli et al., 2008; Pirasteh and Li, 2016). Landslide inventory data, hazard factors, and elements at risk (Fig. 2) are the three main essential layers for landslide hazard and risk (van Westen, 2004). The landslide inventory is the most significant among them because it acquires the location information of landslide phenomena, types, volume, and damage (van Westen et al., 2008).
Historical landslide records and freely accessible databases have been developed for a few countries (e.g. Italy (Guzzetti, 2000), Switzerland, France, Hong Kong (Ho, 2004), Canada, and Colombia). However, difficulties related to completeness in space and time are a drawback (van Westen et al., 2006).

\subsection{Mobile and Web GIS for landslide inventory}

Many improvements in digital mapping and mobile GIS using geospatial technologies have been revealed in the field of data acquisition for landslide hazard and risk, which are mostly open source. The following are examples of these technologies. The British Geological Survey (BGS) digital field mapping system (BGS-SIGMA mobile 2013) includes customized ArcMap 10 and Microsoft Access 2007, which have customized two toolbars for mobile and desktop for digital geological mapping. The mobile toolbar was developed to capture data in the field on tablet PCs with integrated GPS units, and the desktop toolbar focuses on data interrogation, data interpretation, and the generation of finalized data. This is a free software; however, it requires an ArcEditor licence (BGS, 2013). GeoData implemented a mobile application that can add hazards as point markers with an attached image (GeoData, 2016). Another prototype for landslide geomorphological mapping using Open Source Geospatial Foundation software such as MapServer and PostGIS was implemented in the Olvera area, Spain, to improve transportation and construction of roads (Mantovani et al., 2010). This application runs on a desktop and focuses more on the data management system and visualization of data. WbLSIS (Acharya et al., 2015) is a desktop conceptual framework for Web-GIS-based landslide susceptibility for Nepal with an emphasis on data management. Another WebGIS tool was developed for landslide inventory using datadriven SVG (Scalable Vector Graphics) and paper sketch maps (Latini and Köbben, 2005). Temblor is a mobile application for the purpose of visualizing hazard maps online anywhere (Temblor, 2016). Lastly, the global risk data platform by the United Nations Environment Programme (UNEP) is a Web-GIS platform which uses open source to visualize hazard maps and other related data from many countries (UNEP, 2014), but data available in that platform are limited. There are few systems with an option of using mobile technology for landslide and hazard field surveys, while there are sev- 


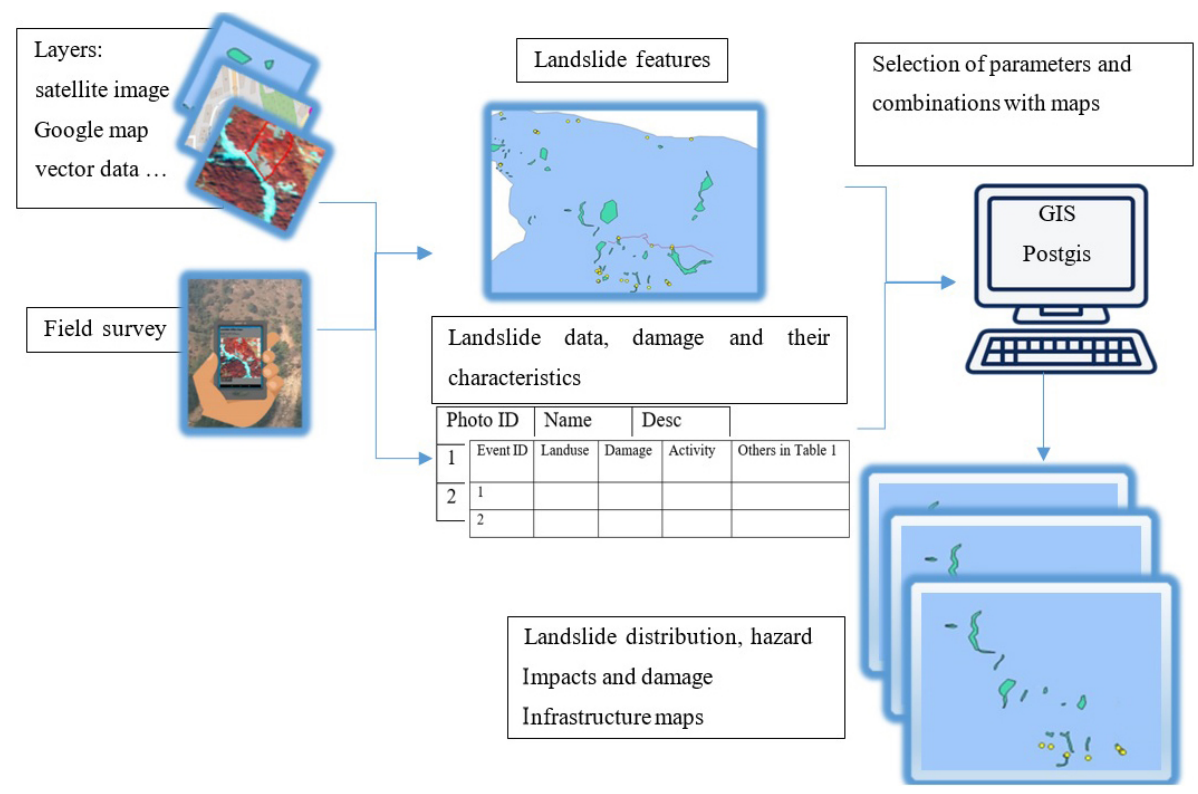

Figure 3. Workflow of ROOMA where coupled image interpolation with field survey leads to valuable maps and a complete database of landslide data and their characteristics. These different maps of landslide distribution, hazard, and damage infrastructure can be produced by manipulation in GIS.

eral related systems using satellite images and mobile GIS (e.g. a mobile GIS application (Bronder and Persson, 2013) for data collection of cadastre - cadaster in American English - mapping using ESRI and Google Android Software Development Kit (SDK)). GeoVille has developed a highly automated land-cover and land-use mapping solution that transforms satellite images into intelligent geo-information (GeoVille, 2016). Ushahidi can build tools to solve unlimited data acquisition, data management, mapping, and visualization challenges using multiple sources such as mobile applications, email, and Twitter (Ushahidi, 2016). All the above-mentioned systems have some disadvantages for our study, such as limited access (BGS, 2013), limited drawing tools (GeoData, 2016) (e.g. point markers only), desktop GIS (Mantovani et al., 2010; Acharya et al., 2015), paper-field systems (Temblor, 2016), and limitations related to visualization and data acquisition (UNEP, 2014). There are different systems in mobile GIS and data collection; however, the possibility of having an open-source mobile application with an added satellite image in offline mode, precise mobile GPS, easy and fast drawing tools, advanced visualization, and a database management system for landslide data collection is quite necessary.

\section{Implementation}

The ROOMA application was developed to complement conventional remote sensing for landslide inventory creation. It is based on a prototype Web and mobile GIS application including an online database to overcome some of the afore- mentioned problems related to landslide database development. This approach compensates the lack of landslide inventories and precise topographic process, and decreases the resources and time needed for data storage and updating. In addition, the combination of the ROOMA data collection in the field with GPS and satellite imagery as source maps can significantly improve the accuracy and quality of input field data. The satellite imagery added to the application significantly eased the exploration of this area and assisted the visual interpretation process. Figure 3 demonstrates the workflow of this method. Image interpolation coupled with field surveys enables the development of a range of GISbased maps including information such as landslide distribution, hazard, and damage infrastructure and a more complete database of landslide data and their characteristics.

Landslides are created and impacted by a large number of components, for example geology, land-cover, land-use practices, and earthquakes. Table 1 illustrates different types of information which can be collected during field mapping of landslides using this application (offline version). The first three rows in this table are compulsory to be filled out in the field survey using the mobile application (landslide ID is given automatically); however, the rest of them can be completed later in the office if needed. This will help the user to save time in the field by recording one specific characteristic of their needs rather than entering all characteristics not needed in their work.

Data on elements at risk in an affected area (houses, schools, inhabitants, road networks, utilities, etc.) form the basis for landslide risk assessments. Importance is com- 
Table 1. Landslide data and their characteristics in the ROOMA database: landslide ID is given automatically, and landslide name and shape are obligatory fields.

\begin{tabular}{lll}
\hline Seq. & Field name & Description \\
\hline 1 & Landslide ID & Numbers of landslides \\
2 & Landslide name & Name of landslide \\
3 & Shape & Point, line, polygon \\
4 & Date of event & 1 January 2015 \\
5 & Date of record & 1 January 2015 \\
6 & Type of material & Debris, earth, rock \\
7 & Type of movement & Slide, flow, fall, rotational slump, flow slide \\
8 & Land-use features & Forest, road, river, agriculture field, house, etc. \\
9 & Damage & Road, house, school, forest, communication line, etc. \\
10 & Triggering factor & Rainfall, earthquake, human activity, others \\
11 & Reactivated? & Yes, no \\
12 & Presently active? & Yes, no \\
13 & Possible reactivation? & Yes, no \\
14 & Hazard degree & No hazard, low, medium, high \\
15 & Possible evolution & Up, down, widening \\
\hline
\end{tabular}

monly placed on data related to houses and people; though in this work, emphasis is given to buildings, road networks, and infrastructure. Generally, data on elements at risk are collected by satellite images and result in the production of versatile databases; however, for this prototype, elements at risk can be recorded directly in the field along with other attributes of landslide event data (Table 1). Elements at risk have different characteristics, including spatial (the feature in relation to the landslide), non-spatial (e.g. temporal data such as inhabitants), and thematic characteristics (e.g. material type of the buildings). Saving land-use features (elements at risk which are damaged or not) along with event data (e.g. hazard and damage to infrastructure) in the field is another advantage of the ROOMA application compared to abovementioned systems.

Figure 4 demonstrates different types of spatial and nonspatial data that are recorded in the ROOMA data model. Each table represents name and type (e.g. integer) of the column. The only mandatory (marked as nn: not null) data to be recorded are the features and name of event; the remaining data can remain null and be filled in later if necessary. Upon the creation of a new "studyarea" table in the online platform, a new database and schema are created dynamically to store all events related to that studyarea. Each studyarea has many "event" tables which can record information on landslides and the viewpoints (as PointGeometry) where this event is mapped. Each event is associated with different feature tables (feature_polygon, feature_line, or feature_point table) and "photo" tables that represent landslides, damage (elements at risk), and photos. The data in these tables are automatically created from GeoJSON text files which have been uploaded to the ROOMA online version. This data model made it easy to query and analyse data based on each studyarea. The case study area for this project is explained in Sect. 5 .

\section{Technology and platform: mobile GIS}

Free and Open-source Software for Geoinformatics (FOSS4G) has significantly improved the efficient mapping and management of post-disaster and impacted areas around the world (UNEP, 2014; Ushahidi, 2016; GeoVille, 2016). GIS can integrate different layers of spatial data on landslide occurrence to define the effects of various parameters.

There are new developments in open-source geospatial technology for visualization and analysis landslides, including (1) digital acquisition and editing tools (Leaflet, 2015), (2) advanced geo-visualization (Boundless Spatial, 2016), (3) enhanced integration with satellite imagery using TileMill (Mapbox, 2016), (4) combination with database management systems (PostgreSQL, 2016; PostGIS, 2015; MySQL, 2015; UserCake, 2016), and (5) amplification of the accuracy by using mobile GPS (Cordova, 2015).

The offline Android component of ROOMA is implemented using Cordova (Cordova, 2015) and PhoneGap (PhoneGap, 2015) (Android environment based on JavaScript) to simplify data collection in the field in remote areas where Internet access is poor. The satellite images are transferred to tiles using TileMill (Mapbox, 2016) and added to the Leaflet map library in both online and offline versions. The online version of this application is based on a client-server software architecture pattern (three-tier architecture), which includes presentation, application, and data layers, developed and maintained independently (Williams and Lane, 2004). Both offline and online versions use clientside jQuery and Leaflet libraries. The different geometrical features (points, lines, and polygons) for landslide data by different descriptive attributes (e.g. type, date, activity, triggering factor, and hazard degree) are given in the GIS format 


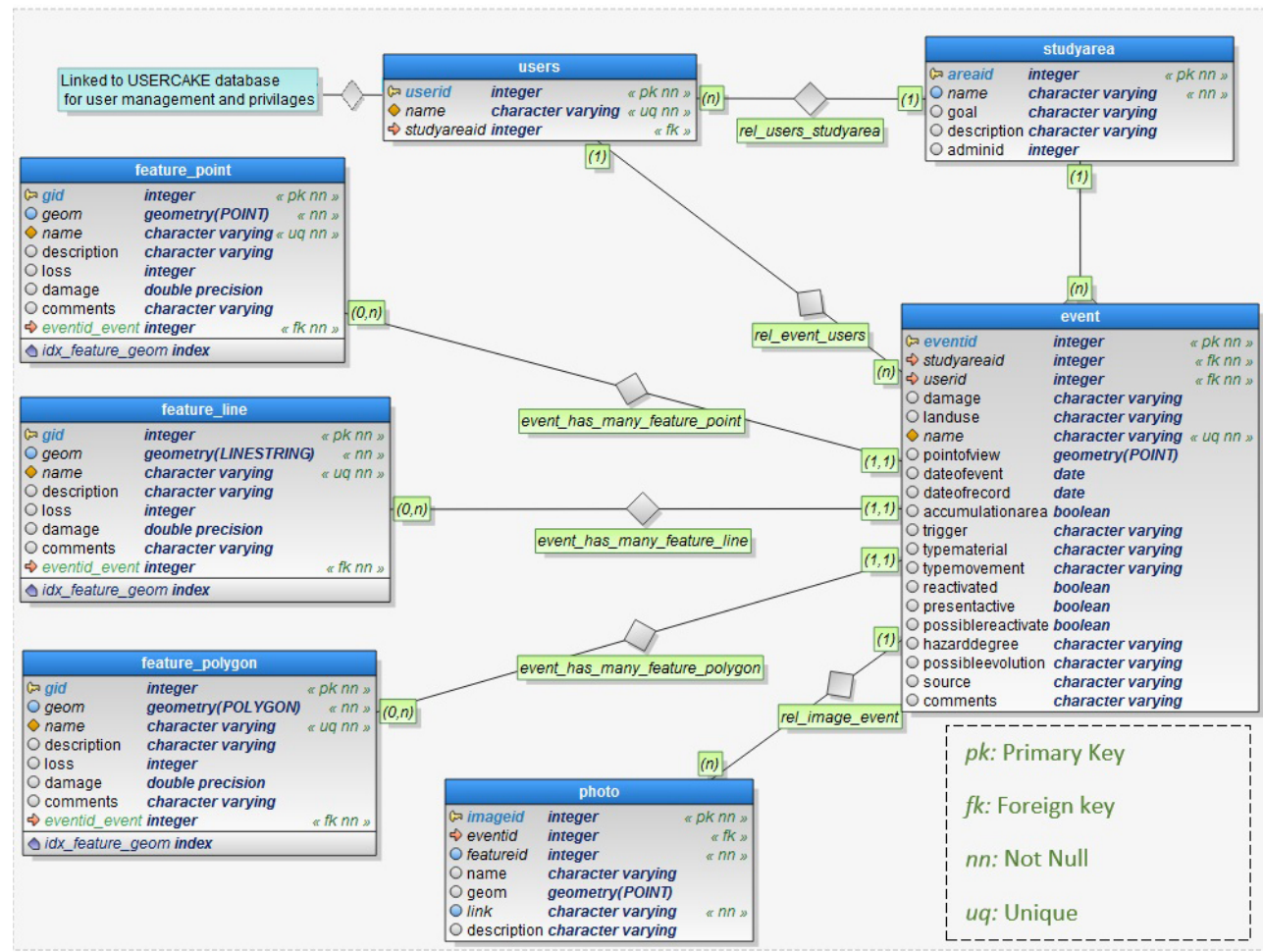

Figure 4. Data model of ROOMA: database is automatically created from GeoJSON text files which have been uploaded to the online version of ROOMA.

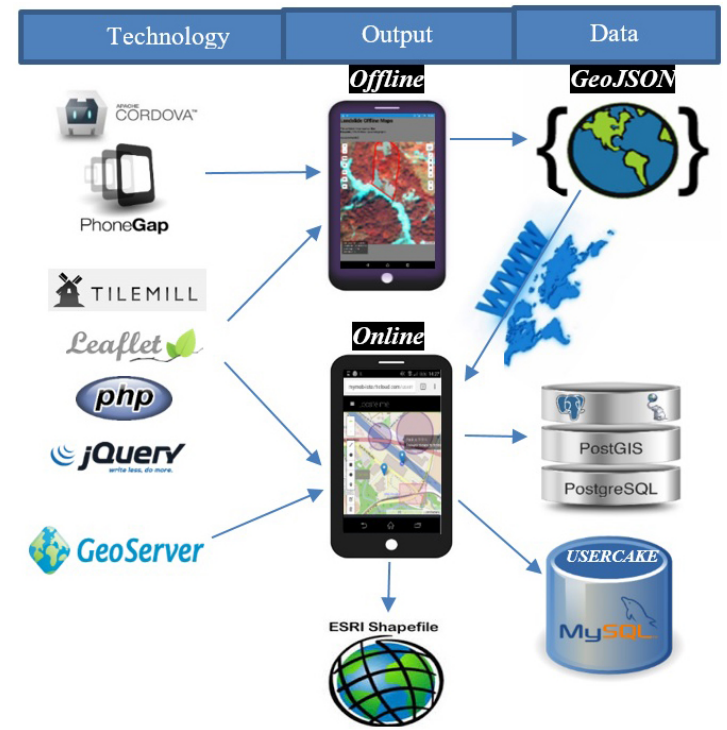

Figure 5. Technology (Cordova and PhoneGap) used by ROOMA, upon which the offline version is built. The online version is based on three-tier architecture which includes the presentation, application, and data layers. The presentation layer is based on Leaflet, jQuery, and JavaScript. Application layer uses PHP to connect to GeoServer and database. The data layer is composed of both MySQL (UserCake) and PostgreSQL (PostGIS). called GeoJSON (GeoJSON is a format for encoding a variety of geographic data structures which is similar to Keyhole Markup Language - KML - format; GeoJSON, 2015) using Leaflet maps. The data can be exported to GeoJSON text files and uploaded through the Internet to the online component where the main database is located. This enables the collection of data from multiple data collectors into the same database. Server-side scripting is based on PHP, which transfers data to the database and saves the output of Leaflet maps in GeoJSON. The geodatabase was designed to incorporate geospatial data acquired in the field, delivered as an input to the system (e.g. type, shape, volume, date, triggering factor, hazard degree) in relation to elements-at-risk data (e.g. building information, road network, damage information) connected to a specific event (Fig. 4). The FOSS4G technologies selected for this module were PostgreSQL 9.4 (PostgreSQL, 2016) and PostGIS 2.1 (PostGIS, 2015) for spatial database management. The GeoServer 2.6 (GeoServer, 2015) module, in connection with a geodatabase (PostGIS), is delivered for visualization and spatial analysis. This component brings a complete and up-to-date description of the different layers, including a landslide event layer, elementsat-risk layer, and detailed information of landslides including event descriptions and photo mapping if any georeferenced photos are uploaded to the online version. Finally, the outcomes are captured and shown through GeoServer and OGC (Open Geospatial Consortium) services such as Web Map 


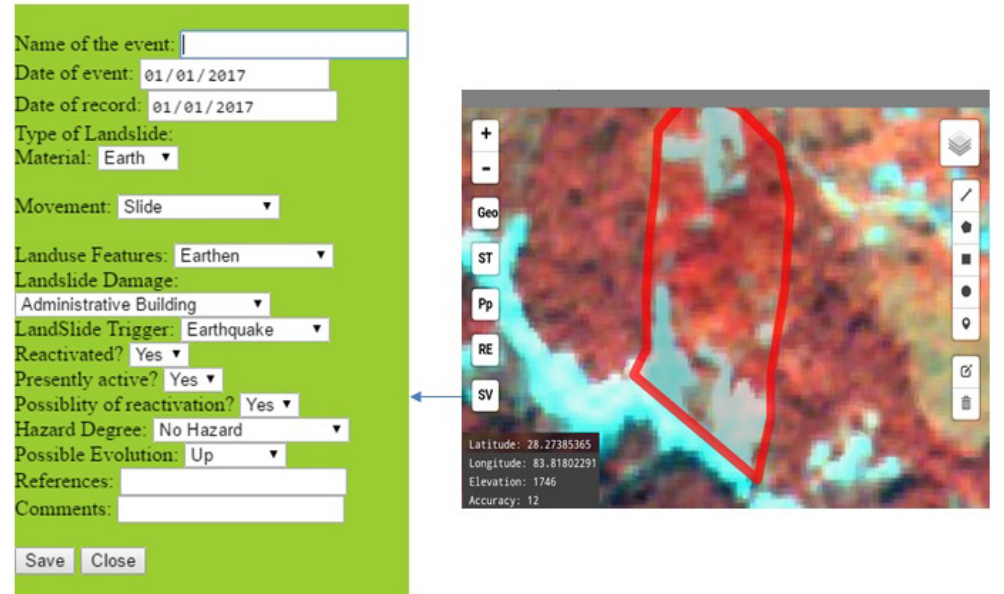

Figure 6. Offline component with a satellite image as the background: geolocation (Geo), stop geolocation (ST), show all the attributes in a pop up window $(\mathrm{Pp})$, reset the map (RE), and save as GeoJSON text (SV) by filling the green from.

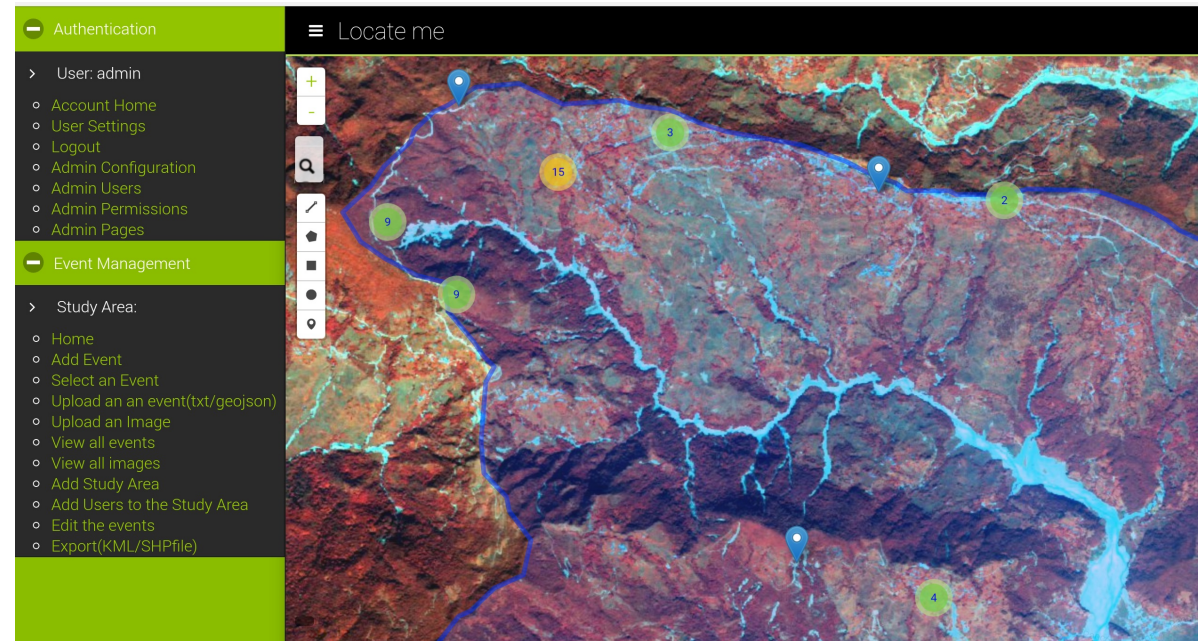

Figure 7. Online component: user authentication and event management as an admin user, with all the recorded events shown as cluster points.

Service (WMS) and Web Feature Service (WFS), as well as being exported as shapefile format and visualized in other GIS software. The UserCake library (UserCake, 2016) is an open-source library in PHP which uses the MySQL database (MySQL, 2015) to improve the user management and authentication. Two types of users are available in this system: public and administrator. Based on their privileges, they can access different components of the online version. For example, only the administrator can define a new studyarea and assign that to different users. Figure 5 displays the technologies and the frameworks of this prototype.

The offline component of ROOMA (Fig. 6) contains the following modules: (1) geolocation using GPS on a mobile or tablet, (2) map with a combination of multi-source base layers (OpenStreetMap, satellite imagery, and vector data can be seen in Fig. 8), (3) map drawer (line, polygon, rectangle, and marker), (4) satellite images as the base layer, and (5) saving options as a GeoJSON text file in the offline mode. The mapping process is quick and easy: various types of satellite images are used as base layers for easy identification of objects on the map (Fig. 8b), upon which different features can be drawn on a map drawer after geolocation. The online component presents more modules in addition to the map and geolocation options (Figs. 7 and 8): (1) saving online events directly to database, (2) photo mapping, (3) photo and event clustering, (4) user privileges, (5) data storage and analysis, and (6) import from/export to shape files.

The user can save or upload these features as one event and define additional characteristics as mentioned in Table 1. Figures 7 and 8 illustrate how an administrator can view different landslide events in the online version with the possibility 


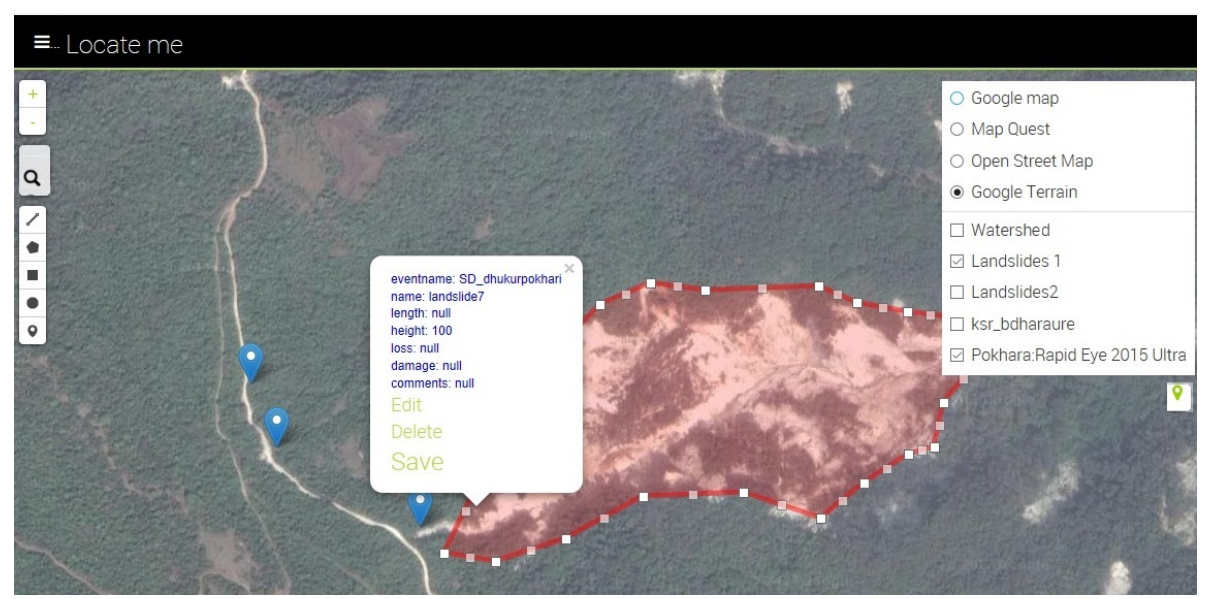

Figure 8. Online component: a landslide event with the options of editing the feature directly into the online database and adding different layers as base layers such as Google Maps, a shapefile, or satellite images (Pokhara: RapidEye 2015).

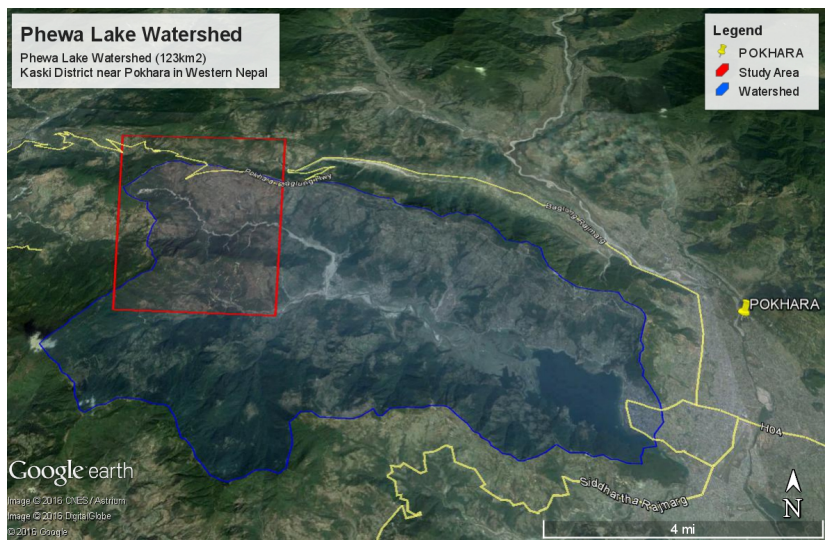

Figure 9. Google Earth image for Phewa Lake watershed, Pokhara, Nepal.

of clustering events (Fig. 7), different base layers (Fig. 8b), and editing events (Fig. 8a) directly into the online database.

\section{Case study}

Many landslide studies have been conducted in the Everest regions (Gupta and Saha, 2009; Bajracharya and Bajracharya, 2010; ICIMOD, 2016; Sato and Une, 2016). The 7.6-magnitude earthquake in Nepal on 25 April 2015 and a series of aftershocks significantly increased the risks of landslides (Collins and Jibson, 2015). Nepal has a high natural geological fragility, which was further increased by the 2015 earthquake, which triggered several thousand landslides (Collins and Jibson, 2015; ICIMOD, 2016). The ROOMA application was tested in the Phewa Lake watershed $\left(123 \mathrm{~km}^{2}\right)$ in western Nepal, Kaski District (Fig. 9), where authors have been monitoring landslides since 2013. An intense rainfall event $(315 \mathrm{~mm}$ in $4 \mathrm{~h})$ killed 9 people
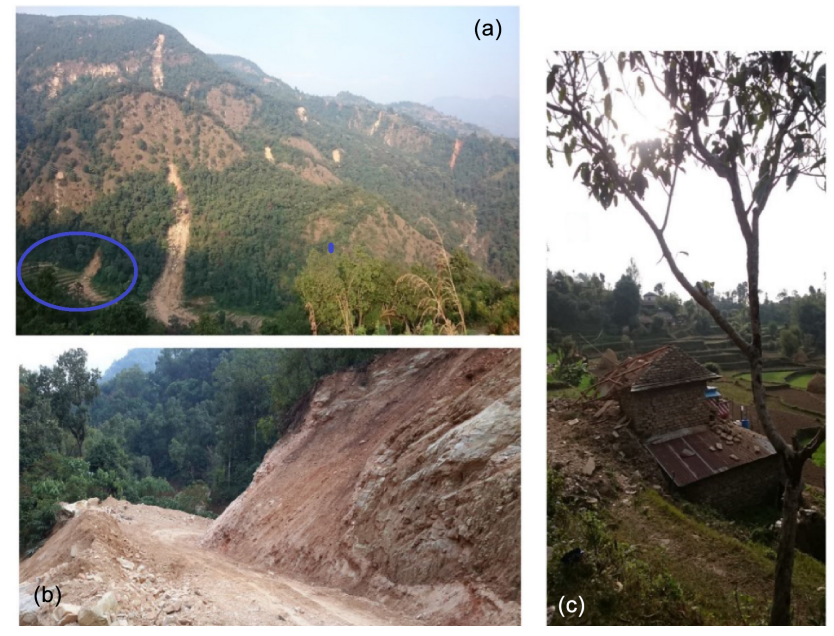

Figure 10. (a) Photo of the area with several landslides near Pokhara watershed in Nepal and the damage to agriculture in the blue circle. (b) Photo of one landslide and damage to the road. (c) Photo of a landslide near a school in the same area.

on 29 July 2015 in Bhadaure - 5 people were killed near Pokhara and another 25 near Lumle in Parbat District (BBC, 2016). It was very hard to identify all landslides and their properties through image interpretation, so the impetus for field mapping was very strong. The ROOMA application was field-tested for a rapid assessment of landslides triggered by this event or reactivated along with their land-use characteristics and damage to houses, schools, roads, rivers, agriculture fields, and forest area (Fig. 10). 

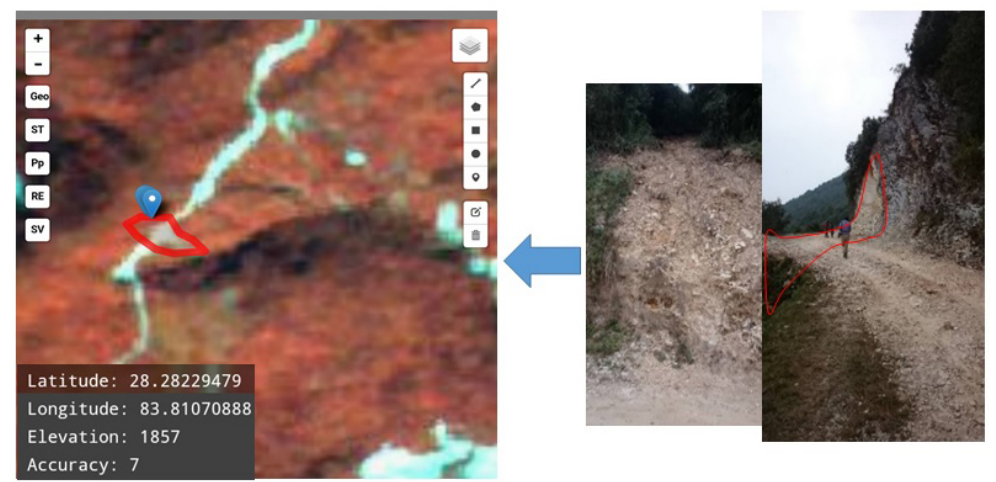

Figure 11. Data collection close to the event where usually a landslide happened near a road and was possible to access.

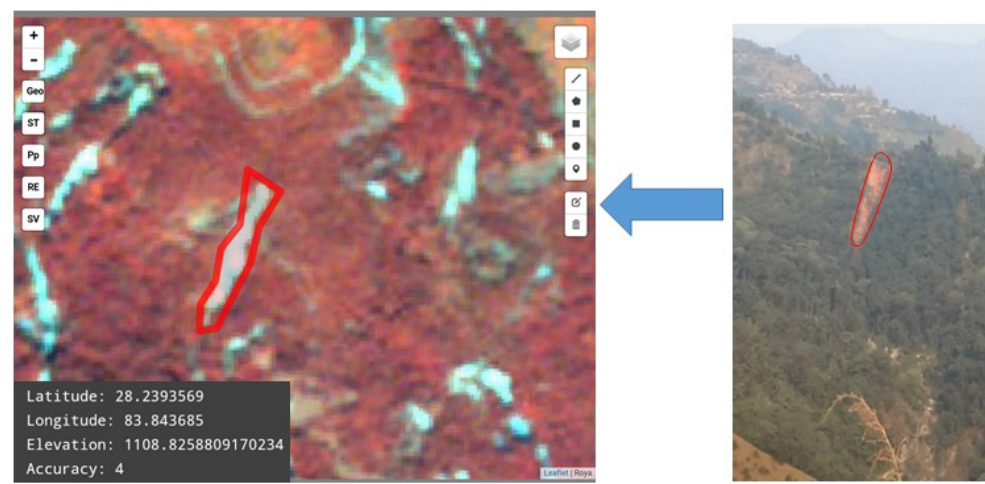

Figure 12. Data collection from a distance where access was difficult but location was easy on the map using geolocation and satellite imagery.

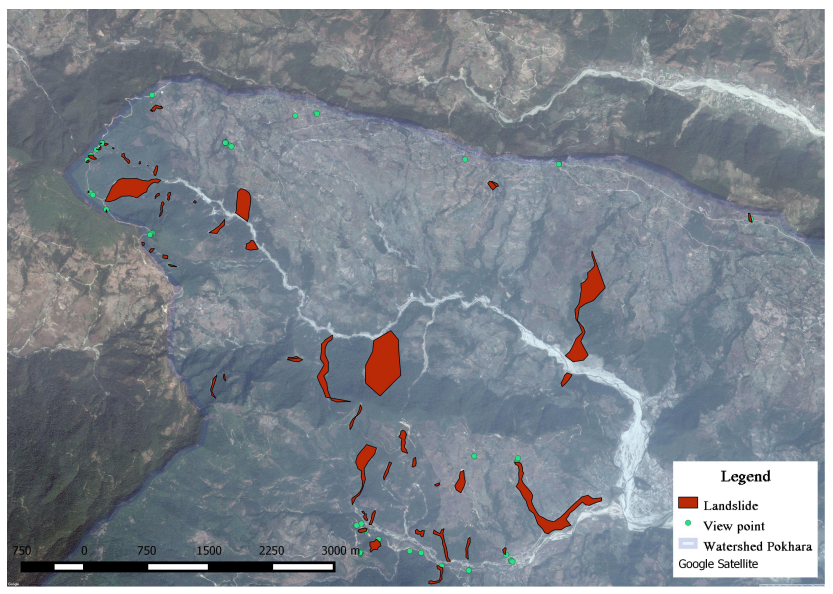

Figure 13. Distribution of landslides in Phewa Lake watershed based on the 2-day data collection.

\section{Results}

Two days of fieldwork were conducted in the Phewa Lake watershed, using the ROOMA application, which used medium-resolution satellite imagery (GeoEye 2015, 5 m res-

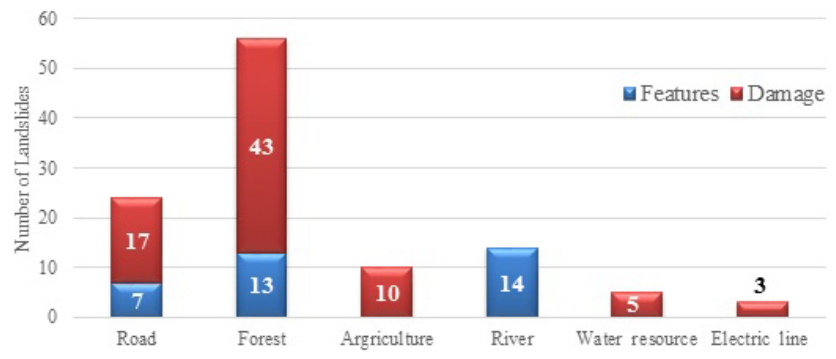

Figure 14. Relationship between features and landslides damage: for example 56 landslides occurred in forest and, of these, 43 damaged the forest (red: damage).

olution) to map 59 landslides. The mapping of landslides (using polygons) was accompanied by data collection on landuse features for each event (e.g. roads, rivers, and forests) to give better indications of surrounding features. Mobile GIS using satellite images and the offline version gives an opportunity to see landslides that already existed and their distribution in that area. The data were collected in the field using the offline version of this platform, either close to a road or from a distance. This enabled easy interpretation of landslides which would have been difficult to access otherwise 
(a)

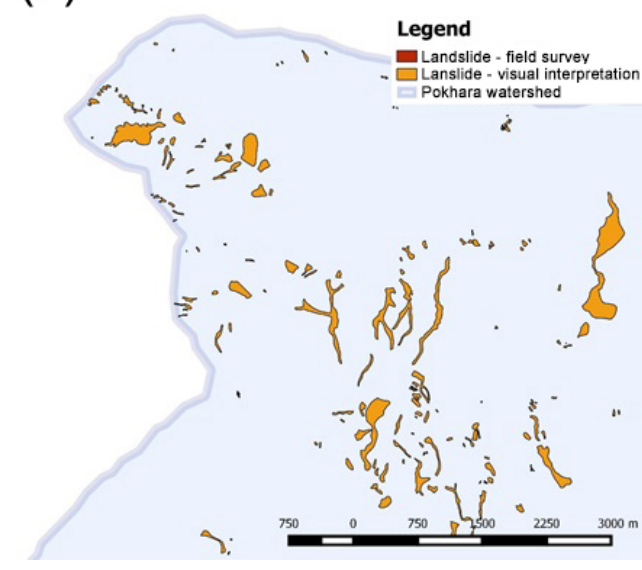

(b)

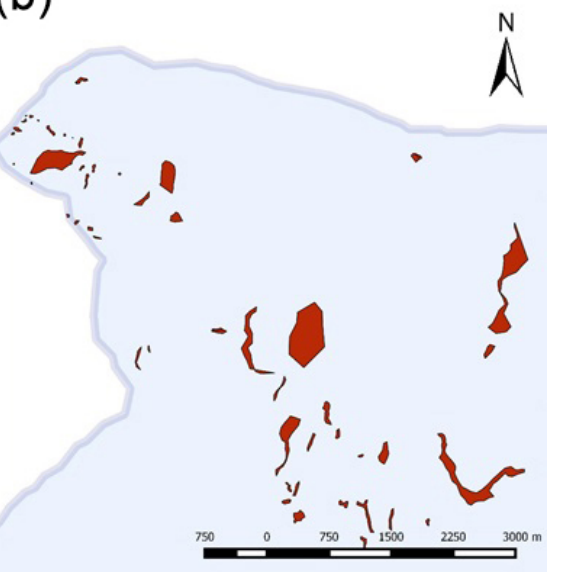

Figure 15. Maps of landslides created by using field survey (red polygons) and visual interpretation (orange polygons).

(Figs. 11 and 12). Figure 11 represents a new landslide documented near the road that was not visible in satellite imagery, and Fig. 12 shows a larger landslide which was located from a distance and clearly visible in image interpretation. Most large landslides were mapped from a distance. Figure 13 shows the distribution of landslides in an area where most landslides occurred in the centre of the Phewa Lake watershed.

All data were uploaded to the online version and then exported to a shape file, while preparation of the maps (Fig. 15) was performed in QGIS2.6.1 (QGIS, 2017). Data obtained from the field survey were successfully analysed in the opensource GIS, such as distribution of landslide type, material, elevation, damages, surface areas, and volume. In this article, we present some selected results. For example, all the information about land-use characteristics and their damages for different landslide was gathered individually in our database and can be useful for more detailed analysis. The graph in Fig. 14 shows that the majority of the landslides occurred near forest areas, and the most damaged areas were related to forest, roads, and agriculture.

Moreover, further analysis of land-use/cover changes has been carried out based on visual interpolation on a multispectral satellite image (SPOT 2016, $2 \mathrm{~m}$ resolution) acquired in 2016 after this field checking. This image improved the quality of the polygons; nevertheless landslides are more difficult to identify as vegetation grows quickly. Principally, this ground-truthing gave the confidence for further mapping (177 landslides mapped afterward) of the additional smaller landslides that were not mapped during the field survey. Figure 15 shows these landslides on the map.

The advantage of a mobile version with field survey compared to mapping using only GIS and high-resolution satellite images (in office) is that some feature characteristics of landslides are not visible in satellite images; therefore, coupling satellite image interpretation with field observation al- (a)

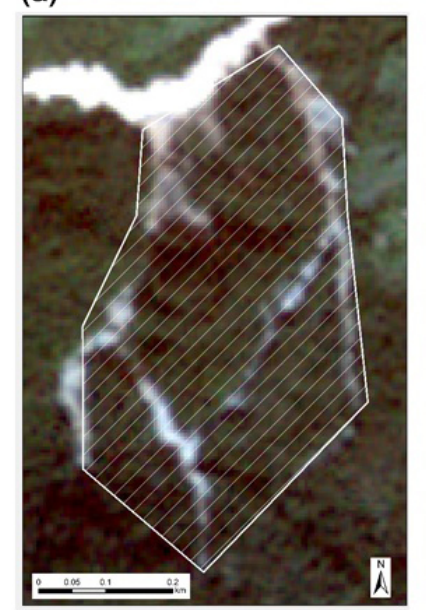

(b)

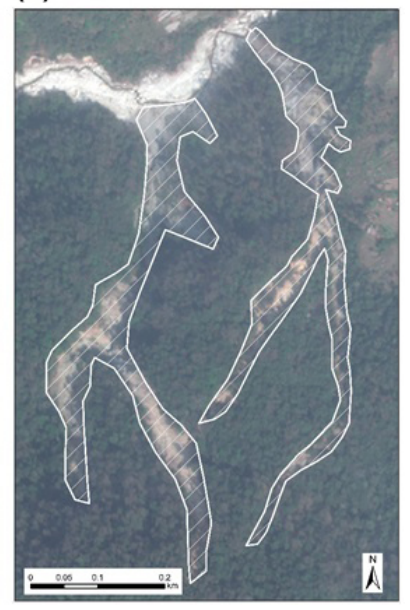

Figure 16. The map on the left shows the lower-resolution image coupled with field survey, and the map on right shows the same area with the detailed mapping in standard GIS. The field survey helped to understand that this is one larger landslide which is covered by vegetation; however office work shows it as two separate landslides and ignored the part of landslide-covered vegetation.

lows one to identify better the type of landslide even when using a medium-resolution satellite image $(\sim 5 \mathrm{~m})$. Figure 16 shows such an example of the detailed mapping in standard GIS permitting the identification of active landslides in the gullies, i.e. debris flow and shallow landslides, while the lower-resolution image coupled with field survey permits the identification of larger landslide. Landslides linked with the gullies are often at the limit of the larger one, indicating landslide activity. 


\section{Concluding remarks and discussion}

Landslide inventories define vulnerability, hazard, landslide susceptibility, and risk by investigating information on type, patterns, distribution, and slope failures (Guzzetti et al., 2012). Earlier publications on landslide hazards show that considerable developments have been accomplished in the last decade: GIS tools are now crucial for landslide assessments; however, the generation of LIMs including elements at risk and larger-scale online databases has been developed but may be out of reach for data-poor countries. The development of an offline rapid mapping application can provide a significant technological leap and save valuable resources. The value of landslide inventories relies on the accuracy and certainty of the information, which is problematic to define (discussed in the Introduction); however, different mapping approaches in open-source geospatial technologies can significantly simplify the production of these maps. Furthermore, the ability to use the open-source software indicates that analyses can be carried out without incurring the high costs associated with software acquisition, a particular advantage for developing countries, researchers, and government officials.

Results for this paper are (1) an Android application, (2) testing the application, (3) analysis and comparison with similar work. This application incorporates rapid, economic, and participatory methods for mapping landslides. It uses satellite images as a multi-source map and enables multiple forms of data collection to finally be collated in a centralized database. Data can be acquired in an offline version using an Android device or an online mode using all browsers on PCs, tablets, and mobiles. The study was applied for mapping landslides in post-earthquake Nepal, but it can be applied for other hazard events such as floods or avalanches. The result has been compared to the same study conducted remotely using image interpolation, and it shows that coupled field mapping with satellite image can improve the quality of landslide hazard and risk mapping. Considering all the difficulties stated in this work (mentioned in the Introduction), for example difficulty accessing the landslide and damage area, we did not face any specific issues during testing of this application. Mapping a landslide is typically carried out based on the experience of the expert; however, through mobile GIS, this application is easy to be run by non-experts and the general public. A combination of satellite data and web-GIS technologies provides an ideal solution for landslide hazard and risk data acquisition, especially when more high-resolution satellite images are freely available. The paper concludes that the ROOMA tool aims to increase the quality and speed of LIMs, which can improve the quality for susceptibility, hazard, risk assessments, and landscape modelling.

The system is being further field-tested for a future improved version; thus, this offline version can be improved by adding more components for distance calculation, continuous lines sketching, recording foot paths, and merging the
GPS-located camera with the azimuth of data to help generate 3-D models of the area.

This study can be enhanced through several of the new developments to ROOMA, e.g. adding topographic data such as digital elevation models (DEMs) and spatial-temporal modelling in order to increase accuracy. More effort is needed to incorporate and define vulnerability components in order to generate risk maps. Finally, it is essential to integrate a spatial decision support system to use such data for landslide hazard and risk assessments for both stakeholders and local authorities.

Data availability. Data are available in shapefile format and can be requested by contacting the first three authors. Video tutorials can be accessed at http://wp.unil.ch/risk/3172-2/ (Risk Analysis Group, 2016). The codes and manual will be available soon within a university link. Please check this for update: https://wp.unil.ch/risk/.

Competing interests. The authors declare that they have no conflict of interest.

Acknowledgements. We would like to thank the Faculty of Geoscience at the University of Lausanne and the EPIC team (Ecosystems Protecting Infrastructure and Communities) for the funding of this project. We appreciate the Institute of Engineering, Department of Civil Engineering at Tribhuvan University in Kathmandu, Nepal, for their supports, friendship, and leadership, and likewise their efforts towards finishing this project. Finally, we would like to thank Cees van Westen at ITC in the Netherlands and Brian G. McAdoo at Yale-NUS College in Singapore for testing the application and for their helpful feedback and comments, some which are mentioned above.

Edited by: P. Tarolli

Reviewed by: two anonymous referees

\section{References}

Acharya, T. D., Shin, M. S., and Yoo, K. W.: A Conceptual Framework for Web-GIS Based Landslide Susceptibility (WbLSIS), Kathmandu, Nepal, 2015.

Bajracharya, B. and Bajracharya, S. R.: Landslide mapping of the Everest region using high resolution satellite images and $3 \mathrm{~d}$ visualization, ICIMOD, Kathmandu, Nepal, 2010.

BBC: available at: http://www.bbc.com/news/ world-asia-33714147/, last access: 10 April 2016.

BGS: BGS SIGMA mobile, available at: http://www.bgs.ac.uk/ research/sigma/download.html (last access: 4 June 2016), 2013.

Boundless Spatial: available at: http://boundlessgeo.com/, last access: 10 July 2016.

Bronder, A. and Persson, E.: Master of Science Thesis in Geoinformatics: Design, Implementation and Evaluation of a Mobile GIS Solution for a Land Registration Project in Lesotho, Royal Institute of Technology (KTH), Stockholm, Sweden, 2013. 
Carrara, A., Cardinali, M., Detti, R., Guzzetti, F., Pasqui, V., and Reichenbach, P.: GIS techniques and statistical models in evaluating landslide hazard, Earth Surf. Proc. Land., 16, 427-445, 1991.

Coe, J. A., Godt, J. W., Baum, R. L., Bucknam, R. C., and Michael, J. A.: Landslide susceptibility from topography in Guatemala. In: Landslides: Evaluation and Stabilization/Glissement de Terrain: Evaluation et Stabilisation, Proceedings of the 9th international symposium on landslides, Rio de Janeiro, 69-78, 2004.

Collins, B. and Jibson, R.: Assessment of Existing and Potential Landslide Hazards Resulting from the April 25, 2015 Gorkha, Nepal Earthquake Sequence, US Geological Survey Open-File Report, US Geological Survey, Virginia, 2015.

Cordova, Cordova Apache: available at: https://cordova.apache. org/, last access: 15 July 2015.

Dai, F., Lee, C., and Ngai, Y.: Landslide risk assessment and management: an overview, Eng. Geol., 64, 65-87, 2002.

Dhakal, A. S., Amada, T., and Aniya, M.: Landslide hazard mapping and its evaluation using GIs: An investigation of sampling schemes for a grid-cell based quantitative method, Photogram. Eng. Remote Sens., 66, 981-989, 2000.

Fell, R., Ho, K., Lacasse, S., and Leroi, E.: A framework for landslide risk assessment and management, in: Landslide Risk Management, Taylor and Francis Group, London, 3-25, 2005.

Galli, M., Ardizzone, F., Cardinali, M., Guzzetti, F., and Reichenbach, P.: Comparing landslide inventory maps, Geomorphology, 94, 268-289, 2008.

GeoData: MGB-LGSD Mobile GIS Application Development Project, User's Manual - Public Application Version 1, available at: http://gdis.denr.gov.ph/mgbpublic/help.pdf, last access: 15 May 2016.

GeoJSON: available at: http://geojson.org/, last access: 15 July 2015.

GeoServer: available at: http://geoserver.org/, last access: 15 July 2015.

GeoVille: available at: http://www.geoville.com/index.php/land_ cover_mapping.html, last access: 13 May 2016.

Gupta, R. and Saha, A. K.: Mapping debris flows in the Himalayas, Geospatial World by Geospatial Media, available at: https://www.geospatialworld.net/article/ mapping-debris-flows-in-the-himalayas/ (last access: 1 July 2016), 2009.

Guzzetti, F.: Landslide fatalities and the evaluation of landslide risk in Italy, Eng. Geol., 58, 89-107, 2000.

Guzzetti, F., Reichenbach, P., Ardizzone, F., Cardinali, M., and Galli, M..: Estimating the quality of landslide susceptibility models, Geomorphology, 81, 166-184, 2006.

Guzzetti, F., Mondinia, A. C., Cardinalia, M., Fioruccia, F., Santangelo, M., and Chang, K.-T.: Landslide inventory maps: New tools for an old problem, Earth-Sci. Rev., 112, 42-66, 2012.

Hammond, C. J., Prellwitz, R. W., and Miller, S. M.: Landslide hazard assessment using Monte Carlo simulation, in: Landslides/Glissements de terrain, edited by: Bell, D. H., Proceedings of the Sixth International Symposium, 10-14 February 1992, Christchurch, New Zealand, Rotterdam, the Netherlands, A. A. Balkema, 2, 959-964, available at: https://forest.moscowfsl.wsu. edu/engr/library/Hammond/Hammond1991c/1991c.html, 1991.

Ho, K.: Keynote paper: Recent advances in geotechnology for slope stabilization and landslide mitigation - perspective from Hong
Kong, in: vol. 2, edited by: Lacerda, W. A., Ehrlich, M., Fontoura, S. A. B., and Sayão, A. S. F., CRC Press, Rio de Janeiro, 1507-1560, doi:10.1201/b16816-216, 2004.

Huabin, W., Gangjun, L., Weiya, X., and Gonghui, W.: GIS-based landslide hazard assessment: an overview, Prog. Phys. Geogr., 29, 548-567, 2005.

Hungr, O., Leroueil, S., and Picarelli, L.: The Varnes classification of landslide types, an update, Landslides, 11, 167-194, 2014.

ICIMOD: available at: http://www.icimod.org/?q=22085, last access: 21 May 2016.

Latini, M. and Köbben, B.: A Web application for landslide inventory using data-driven SVG, in: Geo-information for disaster Management, Springer, Berlin, Heidelberg, 1041-1054, 2005.

Leaflet: available at: http://leafletjs.com/, last access: 15 July 2015.

Mantovani, F., Gracia, F. J., Domenico de Cosmo, P., and Suma, A.: A new approach to landslide geomorphological mapping using the open source software in the Olvera area (Cadiz, Spain), Landslides, 7, 69-74, 2010.

Mapbox TileMill: available at: https://www.mapbox.com/tilemill/, last access: 10 July 2016.

MySQL: available at: https://www.mysql.com/, last access: 10 July 2015.

PhoneGap: Adobe PhoneGap, available at: http://phonegap.com/, last access: 10 July 2015.

Pirasteh, S. and Li, J.: Landslides investigations from geoinformatics perspective: quality, challenges, and recommendations, Geomat. Nat. Hazards. Risk, 1-18, doi:10.1080/19475705.2016.1238850, 2016.

PostGIS: available at: http://postgis.net/, last access: July 2015.

PostgreSQL: available at: https://www.postgresql.org/, last access: 25 July 2016.

QGIS: available at: http://www.qgis.org/en/site/, last access: 25 January 2017.

Risk Analysis Group: Rapid Offline-Online Landslide Mapping tool, available at: http://wp.unil.ch/risk/3172-2/ (last access: 12 April 2017), 2016.

Ruff, M. and Czurda, K.: Landslide susceptibility analysis with a heuristic approach in the eastern Alps, Geomorphology, 98, 314324, 2008.

Safaei, M., Omar, H., Yousof, Z. B. M., and Ghiasi, V.: Applying geospatial technology to landslide susceptibility assessment, Electronic Journal of Geotechnical Engineering, 15, 677-696, 2010.

Sato, H. P. and Une, H.: Detection of the 2015 Gorkha earthquakeinduced landslide surface deformation in Kathmandu using InSAR images from PALSAR-2 data, Earth Planets Space, 68, 113, 2016.

Soeters, R. and van Westen, C. J.: Landslides: Investigation and Mitigation, in: chap. 8 - Slope Instability Recognition, Analysis and Zonation, edited by: Turner, A. K. and Schuster, L. R., National Academy Press, Washington D.C., 129-177, 1996.

Sumaryono, Arifianti, Y., Triana, Y. D., Ika, W., Irawan, W., and Suantika, G.: The Application of Landslide Inventory Data Base of Indonesia (LIDIA) For Supporting Landslide Susceptibility Mapping in Cianjur Regency, West Java, Indonesia, Int. J. Geolog. Sci., 1, 1-9, 2014.

Temblor: Earthquake damage, faults, liquefaction, landslide and seismic hazard rank for home: available at: https://temblor.net/, last access: 25 May 2016. 
UNEP: Global Risk Data Platform 2014, available at: https:// preview.grid.unep.ch/ (last access: 15 May 2016), 2014.

UserCake: available at: http://usercake.com/, last access: July 2016.

Ushahidi: available at: https://www.ushahidi.com/, last access: 9 June 2016.

Van Den Eeckhaut, M., Reichenbach, P., Guzzetti, F., Rossi, M., and Poesen, J.: Combined landslide inventory and susceptibility assessment based on different mapping units: an example from the Flemish Ardennes, Belgium, Nat. Hazards Earth Syst. Sci., 9, 507-521, doi:10.5194/nhess-9-507-2009, 2009.

van Westen, C. J.: Application of Geographic Information Systems to Landslide Hazard Zonation, ITC, ITC Publication Number 15, PhD Dissertation, Technical University Delft, Enschede, the Netherlands, 1993.

van Westen, C. J.: Geo-Information tools for landslide risk assessment: an overview of recent developments, Proceedings of the Ninth International Symposium on Landslides, Rio de Janeiro, Brazil, 2004. van Westen, C. J., van Asch, T. and Soeters, R.: Landslide hazard and risk zonation - why is it still so difficult?, Bull. Eng. Geol. Environ., 65, 167-184, 2006.

van Westen, C. J., Castellanos, E., and Kuriakose, S. L.: Spatial data for landslide susceptibility, hazard, and vulnerability assessment: An overview, Eng. Geol., 102, 112-131, 2008.

Varnes, D.: Landslide hazard zonation: a review of principles and practice, United Nations International, Paris, 1984.

Wieczorek, G.: Preparing a detailed landslide-inventory map for hazard evaluation and reduction, Bull. Assoc. Eng. Geol., 21, 337-342, 1983.

Williams, H. E. and Lane, D.: Database applications and the web, in: Web Database Applications with PHP and MySQL: Building Effective Database, edited by: Oram, A., O'Reilly, Sebastopol, USA, 3-5, 2004.

Zhou, G., Esaki, T., Mitani, Y., Xie, M., and Mori, J.: Spatial probabilistic modelling of slope failure using an integrated GIS Monte Carlo simulation approach, Eng. Geol., 68, 373-386, 2003. 